\begin{tabular}{|c|c|c|}
\hline & Int.J.Curr.Microbiol.App.Sci (2016) 5(1): 812-817 & \multirow{4}{*}{ 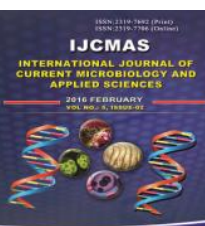 } \\
\hline & \multirow{4}{*}{$\begin{array}{l}\text { International Journal of Current Microbiology and Applied Sciences } \\
\text { ISSN: 2319-7706 Volume } 5 \text { Number 1(2016) pp. 812-817 } \\
\text { Journal homepage: } \underline{\text { http://www.ijcmas.com }}\end{array}$} & \\
\hline & & \\
\hline & & \\
\hline PUBLISHERS & & wwrwijijemas.com \\
\hline
\end{tabular}

Original Research Article

http://dx.doi.org/10.20546/ijcmas.2016.501.083

\title{
Occurrence of Hepatic abscesses in Children hospitalized in Southeastern Brazil: a Retrospective Analysis (2001 to 2012)
}

\author{
Susy Motta Lúcio de Morais ${ }^{1}$, Tracy Lacerda ${ }^{1}$, Thais Premoli Azevedo ${ }^{1}$, Gracilene Maria \\ Almeida Muniz Braga ${ }^{2}$, Emy Hiura ${ }^{1}$, Leandro Abreu da Fonseca ${ }^{3}$, Aline Del Carmen \\ Lopes $^{1}$, Anderson Rocha Aguiar ${ }^{1}$, Frederico Vieira Fróes ${ }^{1}$, Manuela Colares de Andrade, \\ Tatiana da Silva Barbosa, Fausto Edmundo Lima Pereira ${ }^{1}$ and Fabio Ribeiro Braga ${ }^{1 *}$ \\ ${ }^{1}$ Universidade Vila Velha, Vila Velha ES, Brazil \\ ${ }^{2}$ Emescam - Escola Superior de Ciências da Santa Casa de Misericórdia de Vitória, Brazil \\ ${ }^{3}$ Departamento de Veterinária, Universidade Federal de Viçosa, Viçosa, MG, Brazil \\ *Corresponding author
}

Keywords

Liver abscess, Intestinal worms, Helminthiasis, Ascaris lumbricoides, Toxocaracanis, Bacterial infections.

\section{Article Info}

Accepted:

06 December 2015 Available Online: 10, January 2016

\section{A B S T R A C T}

The toxemic form of Schistosomiasis mansoni in children may be a predisposing factor forpyogenic liver abscess(PLA). As in large part of Espírito Santo, Southeast, Brazil, schistosomiasisis endemic and PLA are often diagnosed at the Children's Hospital (Hospital Infantil Nossa Senhora da Glória- HINSG) located in Vitória capital. The aim of the present study was to analyze, through research of medical records, the causes of liver abscesses in children hospitalized at the Children's Hospital(HINSG), from the years2001 to 2012.The medical records of patients admitted to the HINSG during the period described above were revised. For data collection the records belonging to children that had been diagnosed with pyogenic abscess were analyzed.The results identified 68 cases of PLA and 39 of these cases had parasitological stool exams (PSE) recorded in the chart, with 3 positive for Schistosoma mansoni and 29 positive for other intestinal helminths, particularly Ascaris lumbricoides and Trichuris trichiura. It was also evidenced in this study, that the prevalence of intestinal helminthiases decreased in children admitted to the HINSG during that period, and the indices of pyogenic liver abscesses also declined. It was observed that 42 patients had hospital discharge and only 2 died, in the12-year period. Another important result suggests that the origin of patients with pyogenic liver abscess were from the region where ascariasisis not endemic. Through the obtained results, it was concluded that the association between PLA and schistosomiasis proved to be small, there is little overlapping in the geographical distribution of both diseases. On the other hand, the high prevalence of infection by other intestinal helminths and the large number of pyogenic abscesses diagnosed brings to believing that helminth infections with larvae that can migrate to the liver and form granulomas may also be a predisposing factor for liver abscess in children. 


\section{Introduction}

The liver is the largest massif organ in the human body and is interposed strategically between the splanchnic and systemic circulation, receiving venous blood from the portal vein, formed by the mesenteric veins (upper and lower) and the splenic vein, and arterial blood from the hepatic artery, which bring nutrients, toxins, bacteria and viruses into the organ. However, among the various pathologies that may jeopardize the operation of this organ, the liver abscess is mentioned, with etiological causes and multivariate factors. Accordingly, and in particular here, mentioning the study in children, literature has referred to a variety of possible causes for liver abscesses, especially the pyogenic, among which is found that which is referred to as gastrointestinal verminoses (Barnes et al., 1987; Stain et al., 1991; Lambertuci et al., 2001; 2005). The liver abscess is a severe disease that affects 822 individuals per group of 100,000 inhabitants. It constitutes of an infrequent clinical entity, but presents challenges in both diagnosis and treatment. In the last decades, there have been changes in the epidemiology, advances in diagnostics and the emergence of new therapies. The overall incidence of pyogenic liver abscess remained constant an average of six to ten cases per 100,000hospital admissions (Mourah et al., 2006; Ferreira et al., 2007; Branum et al., 1990; Bissada and Bateman, 1991).

It is believed that helminth infections, especially those that produce larvae migrants that can pass through the liver, can also tilt the pyogenic liver abscess and cause modulation to the immune response, as well as granulomas around

The migrant larvae (orits antigens) can function as lesion locator for bacteria in the liver, where a high frequency of helminth infection in cases of pyogenic liver abscess were noted (Santos, 2004; Mota et al., 2004; Crua 2003; Noor et al., 2012; Nkenfou et al.,2013). Crianças têm maior predisposição a essa parasitose, variando a faixa etária.

In this sense, Moreira-Silva andPereira (1998) hypothesized that infection by nematodes with migrating larvae (Ascaris lumbricoides, Strongyloides stercoralis, Ancylostoma duodenale, Necator americanus and Toxocaracanis) could be a predisposing factor forpyogenic hepatic abscess in children. In that study, the authors mentioned that, although there are some missing data in relation to some socioeconomic parameters in affected groups and their comparison, these results support the hypothesis that infection with larvae of migratory helminths by means of tissues can be a predisposing factor for pyogenic abscess in children (Saturnino et al., 2003).

The hepatic abscess is a pathological and infectious condition that affects the liver characterized by the concentration of pus. Classified as: pyogenic versus amoebic. In this case, helminth infections matter due to the resulting mortality and the frequency with which they produce organic deficit, being one of the populations' main debilitating factors, often associating to the chronic diarrhea board and malnutrition, which compromises the physical and intellectual development, impairing children in their activities, both at as well as outside of school. These parasites not only harm children, but also affect other age groups, generating reasoning problems, fatigue, lack of appetite, drowsiness and, in some cases, agitation, among other symptoms (Neves et al., 2005). When faced with a pyogenic liver abscess, it is essential to know the etiopathogeny for proper treatment in which, in addition to antibiotic therapy, drainage of the abscess is included. The two main types of liver abscesses are pyogenic and amebic. 
The pyogenicis responsible for about $90 \%$ of the cases and the amoebic represents only a tenth of cases (Mourah et al., 2006).

In this sense, the evaluation of the quantity of hepatic abscesses found in the medical records of children from 2001to 2012, at the Children's Hospital of Vitória (HINSG), and their possible causes was performed.

The aim of the present study was to analyze, through research of medical records, the occurrence of hepatic abscesses in hospitalized children during the period of 2001-2012in the state of Espírito Santo, southeastern Brazil.

\section{Materials and Methods}

A review was conducted in the medical records of hospitalized patients at the Children's Hospital (Hospital Infantil Nossa Senhora da Glória - HINSG) in Vitória, south eastern Brazil, in the state of Espírito Santo, during the period of 2001 to2012. In the data collection records of children who were diagnosed with pyogenic abscess were analyzed. The HINSG is the only pediatric referral hospital in the state, attending children of all municipalities, representing the clientelea good sampling of the pediatric population seeking medical care and requiring hospitalization in Vitória, state of Espirito Santo.

In reviewing of the medical records, data on the origin of the patients, their physical examinations, laboratory exams (blood count, serology, and parasitological stool tests) and imaging exams(ultrasound and computed tomography), surgical procedures (puncture, drainage, and laparotomy) were registered. The results obtained are the object of study for the development of this research.
The prognostic factors analyzed in this study were: clinical findings, age, abscess etiology, lesion size, laboratory abnormalities, bacteriology, employed treatment, and outcome. Data on the patients' origins and exams which demonstrated the existence of liver abscess and its possible causes were noted. For all patients a detailed clinical history was held.

The hepatic abscesses were classified according to their etiology and were discriminated to their possible causes. In addition to the description of abscess type, other data were cataloged for the purpose of conducting a more intensive verification of the cause and for correlation to the presumptive diagnosis of helminth infection. The data were interpreted using descriptive statistics (absolute and relative frequency) and correlation of the most common causes of liver abscesses, observed in the medical files was performed.

\section{Results and Discussion}

The results of this study demonstrated that most children with liver abscess due to ascariasis lived in areas without basic sanitation (water supply, sewage, urban cleaning, solid waste management and storm drainage), an environment that favors verminoses, located in the peripheries of the municipalities of Vitória (Cariacica and Serra)followed by the states interior cities, as shown in Figure1, or with basic sanitation but without adequate hygiene habits, which can obscure the data in Figure2.It was evident, in this study, that the prevalence of intestinal helminthiases decreased in the children admitted to HINSG and the indices of pyogenic liver abscesses also declined. It was observed that 42 patients had hospital discharge and only 2 died, in the12-year period at the Children's Hospital (HINSG) in Vitória -ES. 
On the other hand, one of the complications that occur by migration of A.lumbricoides is liver abscess secondary to its rise to the biliary tract and also due to their life cycle, generating respiratory compromise, which in this study, 21 records with Ascaris lumbricoides either via oral/ anal elimination or evidenced in bile ducts was obtained. Twenty-four records with respiratory compromise and 16were interpreted as Loeffler's syndrome, as shown in Figure.4. The diagnosis is based on the visualization of helminths by imaging exams (ultrasound and computed tomography), detection of eggs in the parasitological stool examination (HPJorKato-Katz methods), and medical history(Santos, 2004).

Among the sixty-eight analyzed medical records of patients admitted to the HINSG, International classification of diseases / ICD), ICD-1 of the fifty-nine, thirty-seven had liver abscess. In ICD-2, of nine hospitalized patients, only seven had liver abscess. In ICD-3, of three hospitalized patients, two had liver abscess, totaling forty-six hospitalizations with liver abscess; but, while doing field research, absence of two medical records, and two more, with diagnosis of liver abscess were noted, with normal ultrasounds and treated as such. And twenty-two records were of other pathologies, dropping to 42 analyzed medical records. Except for one case, all other diagnoses were confirmed by abdominal ultrasound, during surgical drainage, and one case during necropsy. As predisposing factors, there was the presence of worms, biliary obstruction by Ascaris, and systemic infection from skin lesions.

Data from the stool examination, noted in the medical records, showed positive for helminths, especially for A.lumbricoides. Cases were observed where there was elimination of A.lumbricoides, either by mouth or by the anus, with negative parasitological stool exams, and positive parasitological stool exams without elimination. The origin of patients with pyogenic liver abscess showed that many cases were from the region where ascariasis is not endemic.

Most cases of pyogenic liver abscess reported here come from the urban periphery of Vitória, where hygiene conditions are poor, being the risk to helminth infections high, including by Toxocara canis, due to the large existing dog population. In fact, intestinal helminth infection due to Ascaris occurred in $66.6 \%$ of cases where a fecal exam was noted in the medical record (Musso et al., 1996).

These results confirmed that the frequency of pyogenic abscesses usually in children with immune deficiency does not differ in the frequency of parasitic disease in children seen in the medical charts. In cases of pyogenic liver abscess, it is shown that the vast majority was from the municipalities of Cariacica and Serra. Only a few cases were from other municipalities. Of all the records used for the analysis, $63 \%$ are male, and $37 \%$ female. The patients were hospitalized, mostly from 21 to 30 days. The hospitalization period was considered long, as shown in Figure 10.

In the records used for the analysis, $90 \%$ showed incidence of fever and only $10 \%$ had no fever. Of the total medical charts analyzed, $73 \%$ of them showed Ascaris and $27 \%$ of them did not. Of the records analyzed, it was found that $71 \%$ of them showed eosinophilia and $29 \%$ of them did not. Considering the patients with liver abscess $11 \%$ of them were positive for Toxocaracanis. Of the records that were positive for liverabscess 30 of them showed eosinophilia, being 21 of these positive for A.Lumbricoides and 16 with respiratory compromise. 
Helminths are macroparasites and, depending on infection, they can produce mechanical obstruction in the intestine and cause diseases such as liver abscesses. The progressive reduction of the number of children with verminoses cared for in the HINSG is parallel to the reducing number of pyogenic liver abscess, which confirms the idea that infections with nematodes actually are a risk factor in for staphylococcal infections in children.

It is known that health education for children is an essential factor for control of ascariasis, especially considering the characteristics of the disease during childhood: high prevalence, high percentage of resistance to treatment, high egg elimination rates, and high levels of reinfection. Therefore, it is suggested that all the inhabitants of these municipalities adopt preventive education measures, since the child has an important role in maintaining the A. lumbricoides cycle and their bad habits play a decisive role in the spreading of this disease and the complication of others.

In conclusion, in this study, the main causes of liver abscesses detected were verminoses, which have high prevalence, especially in poor populations and children, due to precarious conditions of sanitation, housing, and education. It was concluded that there is a high prevalence of A.lumbricoides in the children analyzed, indicating an alarming situation. Thus, there is a clear necessity for implementing government programs that attempt to reverse the issue of poor hygienic and sanitary conditions of the municipalities that stood out in this study.

\section{Conflict of Interest}

The authors declare that they have no conflict of interest.

\section{Acknowledgment}

The authors thank, FAPES, CNPq, CAPES and FAPEMIG for their financial support.

\section{References}

Barnes, P.F., Decock, K.M., Reynolds, T.N., Ralls, P.W. 1987. A comparison of amebic and pyogenic abscesses of the liver. Medicine., 66:472 $\neg 83$.

Branum, G.D., Tyson, G.S., Branum, M.A.,Meyers, W.C.Hepatic abscess: change in etiology, diagnosis and management. Am Surg., 212: 655662, 1990.

Bissada, A.A., Bateman, J. 1991. Pyogenic liver abscess: a 7 year experience in a large community hospital. Hepato gastroenterology., 38:317.

Crua, A.S. 2003. Parasitoses intestinais. In: Ferreira, C.T.; Carvalho, E.; Silva, L.R. Gastroenterologia e Hepatologia em pediatria: diagnóstico e tratamento., Rio de Janeiro: Medsi, p. 185-97.

Ferreira, S., Barros, R., Santos, M., Batista, A., Freire, E.,Reis, E., Correia, J., Oliveira, J. 2007. Abscesso hepático: casuística de 19 anos. GE - J. Port. Gastrenterol., 14: 128-133.

Lambertucci, J.R., Rayes, A.A.,Serufo, J.C., Nobre, V. 2001. Abscessos piogênicos e doenças parasitárias. Revista do Instituto de Medicina Tropical de São Paulo., 43: 67-74.

Lambertucci, J.R., Sousa-pereira, S.R., Silva, L.C. 2005. Mielócitosr radiculopatia na esquistossomose mansônica aguda. RevSocBrasMed Trop., 38: 277-278.

Maher jr, J.A., Reynolds, T.B., Yellin, A.E. 1979. Successful medical treatment of pyogenic liver abscess. Gastroenterology., 77:618.

Mourah, M., Hinds, R., Verma, A., Yu, D., 
Samyn, M., Mieli-vergani, G. 2006. Liver abscesses in children: a single center experience in the developed world. J. Pediatr Gastro enterol Nutr., 42:201-6.

Moreira-silva, S.F., Leão, M.E., Mendonça, H.F.S., Pereira, F.E.L. 1998. Prevalence of antiToxocara antibodies in a random sample of inpatients at a children's hospital in Vitória, Espirito Santo, Brazil.Revista do Instituto de Medicina Tropical de São Paulo, 40:259-61.

Mota, J.A.C., Penna, F.J., Melo, M.C.B. 2004. Parasitoses intestinais. In: LEÃO, E., Corrêa, E.J., Viana, M.B., Mota, J.A.C., eds.Pediatria Ambulatorial., $5 . \quad$ ed. B. H.: Coopmed.

Musso, C., Pereira, F.E.L., Dettogni, R.V., Ferreira, M.A.B. 1996. Abscesso piogênico do fígado e esquistos somose mansônica: observações no Estado do Espírito Santo. Revista da Sociedade Brasileira de Medicina Tropical., 29:359-362.

Neves, D. P., Melo, A. L., Linardi, P. M. 2005.Parasitologia Humana, 11.
ed.Sao Paulo: Atheneu, 49p.

Noor, R. et al., 2012. Frequency of opportunistic and other intestinal parasitic infections in patients infected with human immunodeficiency virus in Bangladesh. Tzu Chi Medical Journal., 24:192-195.

Nkenfou, C. N., Nana, C. T., Payne, V. K. 2013. Intestinal Parasitic Infections in HIV Infected and Non-Infected Patients in a Low HIV. Prevalence Region, West Cameroon. PLOS ONE., Vol. 8, Issue 2.

Stain, S.C., Yellin, A.E., Donovan, A.J., Brien, H.W. 1991.Pyogenic liver abscess.ARCH SURG, 126:991-96.

Santos, C.S.R. 2004. Abscesso hepático fúngico: análise de dados. $G M$ Bahia., 74:2:127-144.

Saturtino, A.C.R.D., Nunes, J.F.L., Silva, E.M.A. 2003. Relação entre a ocorrência de parasitos intestinais e sintomatologia observada em crianças de uma comunidade carente de Cidade Nova, em Natal, Rio Grande do Norte, Brasil. Revista Brasileira de Análises Clínicas., 35:85 - 87.

\section{How to cite this article:}

Amany Susy Motta Lúcio de Morais, Tracy Lacerda, Thais Premoli Azevedo, Gracilene Maria Almeida Muniz Braga, Emy Hiura, Leandro Abreu da Fonseca, Aline Del Carmen Lopes, Anderson Rocha Aguiar, Frederico Vieira Fróes, Manuela Colares de Andrade, Tatiana da Silva Barbosa, Fausto Edmundo Lima Pereira and Fabio Ribeiro Braga. 2016. Occurrence of Hepatic abscesses in Children hospitalized in Southeastern Brazil: a Retrospective Analysis (2001 to 2012). Int.J.Curr.Microbiol.App.Sci.5(1): 812-817 http://dx.doi.org/10.20546/ijcmas.2016.501.083 